\title{
A ESTIMATIVA DO FLUXO DE CAIXA DAS OPERACÕES REPRESENTA O REAL FLUXO DE CAIXA DAS OPERAÇÕES?
}

\author{
Bruno Meirelles Salotti \\ Doutorando em Controladoria e Contabilidade pela FEA-USP \\ E-mail: bruno.salotti@fipecafi.fea.usp.br \\ Marina Mitiyo Yamamoto \\ Professora Doutora do Depto. de Contabilidade e Atuária da FEA-USP - Campus Capital \\ E-mail: marinamy@usp.br
}

\section{RESUMO}

A Demonstração dos Fluxos de Caixa (DFC) é uma valiosa ferramenta para analisar os efeitos das atividades operacionais, de investimento e de financiamento no fluxo de caixa de um determinado período. A divulgação dessa demonstração contábil não é obrigatória no Brasil. Portanto, quando a informação relacionada ao Fluxo de Caixa Operacional (FCO) é requerida, mas não está disponível, ela é estimada.

Este estudo avalia a adequação de uma técnica existente para estimar o FCO, baseada em ajustes provenientes das outras demonstrações contábeis (Balanço Patrimonial, Demonstração do Resultado do Exercício e Demonstração das Origens e Aplicações de Recursos).

Inicialmente, este estudo relaciona o FCO estimado a argumentos lógicos para avaliar conceitualmente se tal medida pode ser uma aproximação razoável do FCO extraído da DFC. Posteriormente, da base de dados da Revista "Melhores e Maiores", são verificadas as empresas do mercado brasileiro que espontaneamente publicaram a DFC em 2000 e 2001. O FCO estimado é calculado e, então, comparado com o FCO divulgado para validar, empiricamente, a técnica de estimação mencionada acima, demonstrando a sua real eficiência, principalmente por meio do teste de Wilcoxon.

Palavras-chave: Balanço Contábil, Fluxo de Caixa, Contabilidade.

\section{ABSTRACT}

The Cash Flow Statement (CFS) is a valuable tool to analyze the effects of operational, investment and financing activities on the cash flow in a certain period of time. The disclosure of this Financial Statement is not mandatory in Brazil. Thus, when information related to the Operating Cash Flow (OCF) is needed but not available, it is estimated.

This study evaluates the adequacy of a specific OCF estimation technique, based on adjustments from the other financial statements (Balance Sheet, Profit and Loss Statement and the Funds Statement).

First, this study relates the estimated OCF to logical arguments and numerical simulations in order to conceptually evaluate whether this measure would be a reasonable approximation of the OCF that is taken from the CFS. Next, a set of companies in Brazil is evaluated, which were included in the "Exame - Melhores e Maiores" magazine data base and spontaneously published the CFS in 2000 and 2001. The estimated OCF is calculated and, then, compared with the disclosed OCF to empirically validate the estimation technique quoted above, pointing out its actual efficiency, mainly based on the Wilcoxon test.

Keywords: Balance Sheet, Cash Flow, Accounting. 


\section{INTRODUÇÃO}

Este estudo trata da discussão e avaliação do Fluxo de Caixa das Atividades Operacionais (FCO), utilizado para uma série de propósitos, como tomadas de decisões gerenciais, avaliação de empresas e análises de desempenho.

Uma das maneiras de obter o FCO é por meio da verificação da Demonstração dos Fluxos de Caixa (DFC), dividida em três grandes grupos: fluxos das atividades operacionais, de investimento e de financiamento. Além da informação desejada ser, claramente, evidenciada em tal demonstração, o usuário possui maior probabilidade de que a medida esteja correta, pois, entre outros motivos, é preparada pela própria empresa.

A divulgação da DFC já é obrigatória em diversos países desde a década de 1980. Por exemplo, o Canadá a tornou obrigatória em 1985. Os Estados Unidos, em 1987. A norma internacional do IASB (International Accounting Standards Board) relacionada à DFC foi aprovada em 1992. No Brasil, a divulgação da DFC não é exigida das empresas que publicam as suas demonstrações contábeis. Entretanto, algumas empresas do mercado brasileiro divulgam os Fluxos de Caixa de maneira voluntária.

Os profissionais do mercado conhecem técnicas para estimar o FCO e as utilizam, por vezes de modo indiscriminado, para o atendimento de seus propósitos. Neste trabalho, é abordada apenas uma dessas técnicas: o cálculo do FCO derivado de ajustes contábeis. Este é obtido por meio da utilização das outras demonstrações contábeis - Balanço Patrimonial, Demonstração dos Resultados do Exercício, Demonstração das Mutações do Patrimônio Líquido e Demonstração das Origens e Aplicações de Recursos - e se aproxima do método indireto de cálculo do FCO. Apesar da nomenclatura "ajuste contábil" ser utilizada, as referidas demonstrações contábeis não são ajustadas ou alteradas para que o FCO possa ser calculado. Tais demonstrações servem apenas como base informativa para o cálculo do FCO.

$\mathrm{O}$ estudo se divide em duas partes. Na primeira, são apresentadas discussões conceituais a respeito do cálculo do FCO. Na segunda parte, é descrita a pesquisa empírica realizada com empresas que atuam no mercado brasileiro, proposta a identificar o
FCO de companhias que publicaram a DFC nos exercícios findos em 31 de dezembro de 2000 e 31 de dezembro de 2001 e utilizar a análise de histogramas e o teste de Wilcoxon para comparar o FCO publicado com o estimado.

Ao final do trabalho, são apresentadas as conclusões obtidas com a comparação entre os resultados das duas etapas descritas acima.

\section{SITUAÇÃO-PROBLEMA}

O fato de a divulgação da DFC não ser obrigatória no Brasil estimula a utilização de meios alternativos para a obtenção do FCO, por exemplo. Com isso, medidas como o FCO derivado de ajustes contábeis são utilizadas pelo mercado como substitutas do FCO publicado, sem que sejam avaliadas adequadamente por essa capacidade.

Assim, este estudo busca a resposta de tal avaliação, a fim de que o usuário da contabilidade possa se valer de informações que refletem a realidade da empresa. Para a busca dessa resposta, o sistema de hipóteses a ser considerado é caracterizado dessa maneira:

$\mathrm{H}_{0}: \mathrm{FCO}$ publicado $=\mathrm{FCO}$ alternativo

$\mathrm{H}_{1}$ : $\mathrm{FCO}$ publicado $\neq \mathrm{FCO}$ alternativo

A relação entre as medidas estudadas é avaliada tanto conceitualmente, por meio da apresentação e discussão de conceitos e pesquisas existentes sobre o tema, como de modo empírico, por meio de uma pesquisa, descrita na seção anterior.

\section{OBJETIVOS E JUSTIFICATIVAS}

Este trabalho avalia se existe ou não diferença significativa entre o FCO divulgado pela empresa e o FCO calculado a partir de ajustes contábeis.

O presente trabalho justifica-se em virtude da ampla utilização das medidas alternativas do FCO, tornando-se necessária a sua respectiva validação teórica e empírica.

\section{DELIMITAÇÃO}

Este trabalho delimita-se ao estudo teórico e empírico da DFC, especialmente da medida FCO. Apesar dessa demonstração ser a possível substituta da DOAR, ela é comentada apenas nos aspectos 
essenciais, não sendo escopo do trabalho a discussão de tal substituição.

A norma do IBRACON sobre a elaboração e divulgação da DFC surge em abril de 1999'. Se a pesquisa abrangesse balanços anteriores a esta data, 0 risco de obtenção de demonstrações contábeis com diferentes padrões seria maior ${ }^{2}$. Considerando que, quando do encerramento do exercício findo em 31 de dezembro de 1999, a norma era recente, foram adotados apenas os períodos de 2000 e 2001.

Tais demonstrações não estão corrigidas pelos efeitos da inflação. Esse procedimento não vem sendo realizado desde as publicações do período de 1996 em virtude da publicação da lei 9.249/95, que extinguiu a correção monetária nas demonstrações contábeis brasileiras. Posteriormente, algumas empresas vêm publicando, espontaneamente, as suas demonstrações corrigidas, porém em quantidade insignificante ${ }^{3}$.

\section{METODOLOGIA}

Quanto aos objetivos, esta pesquisa é classificada como explicativa. Como conceitua Andrade (1999, p. 18), "esse é um tipo de pesquisa mais complexo, pois, além de registrar, analisar, classificar e interpretar os fenômenos estudados, procura identificar seus fatores determinantes." Tal identificação é de fundamental importância para os resultados deste estudo, pois se objetiva a explicação das semelhanças e diferenças existentes entre o FCO extraído da DFC publicada e o FCO derivado de ajustes contábeis.

O método de abordagem mais apropriado para a consecução dos objetivos é o hipotético-dedutivo. Isso se justifica, pois o estudo é composto da validação tanto teórica quanto empírica, visto que, na primeira parte, buscam-se soluções teóricas para o problema proposto e na segunda, testes de falseamento, obtidos por meio da observação empírica.
Quanto aos métodos de procedimento, esta pesquisa está orientada pelo método comparativo e o estatístico, pois o primeiro serve para a comparação entre a medida publicada e as alternativas. Já o segundo é útil para a validação estatística das hipóteses apresentadas. Dessa maneira, a pesquisa empírica é analisada de modo estatístico, por meio da execução de teste de hipóteses ${ }^{4}$.

Para a obtenção das demonstrações contábeis dos períodos findos em 31 de dezembro de 2000 e 2001, foi utilizada a base de dados da Revista "MeIhores e Maiores"'.

\section{FLUXO DE CAIXA OPERACIONAL DERIVADO DE AJUSTES CONTÁBEIS}

\subsection{Conceito}

A tentativa de estimar o fluxo de caixa das operações (calculando o FCO derivado de ajustes contábeis) vem sendo executada pelos usuários da Contabilidade há algum tempo, já que a divulgação da DFC (que apresenta explicitamente o FCO, eliminando a necessidade do processo de estimação desse fluxo) foi adotada recentemente. Nos Estados Unidos, antes da publicação do SFAS-95 (Statement of Financial Accounting Standards n ${ }^{\circ} 95$ - Statement of Cash Flows), os usuários da contabilidade já se valiam de um cálculo feito a partir das demais demonstrações contábeis que tentava aproximar-se de uma medida de fluxo de caixa operacional. De 1988 em diante, porém, esse cálculo passou a ser, de certa maneira, desnecessário, uma vez que a divulgação da DFC tornou-se obrigatória naquele país.

No Brasil, os usuários continuam a se utilizar dessa metodologia de cálculo, já que a divulgação da DFC ainda não é obrigatória, apesar de algumas empresas a disponibilizarem nos seus relatórios contábeis. Discutindo a questão da competência

\footnotetext{
${ }^{1}$ Normas e Procedimentos Contábeis, número 20, pronunciamento emitido em abril de 1999 pelo IBRACON - Instituto dos Auditores Independentes do Brasil.

${ }^{2}$ Entende-se que tal risco não foi totalmente eliminado já que a norma é relativamente recente, assim tanto auditores como contadores ainda podem estar em fase de aprendizado.

${ }^{3}$ Em um ambiente inflacionário, a falta de correção monetária pode afetar significativamente a qualidade informacional das demonstrações contábeis, mesmo que os níveis de inflação sejam baixos. A esse respeito, vide Fipecafi (1994), Santos (1997), Martins, Santos e Gelbcke (2003), Iudícibus, Martins e Gelbcke (2003), e Salotti (2003).

${ }^{4}$ Para mais detalhes sobre a pesquisa explicativa, vide Andrade (1999, p. 18), Castro (1978, p. 66) e Gil (1987, p. 47). A respeito do método de abordagem hipotéticodedutivo, vide Andrade (1999, p. 24), Gil (1987, p. 28-31), Lakatos e Marconi (1985, p. 91-96;102) e Vergara (1998, p. 45). Sobre os métodos de procedimento, vide Andrade (1999, p. 25/6), Gil (1987, p. 34-36) e Lakatos e Marconi (1985, p. 102-104).

${ }_{5}^{5}$ A revista "Melhores e Maiores" ("Exame" - Editora Abril) publica anualmente um ranking elaborado pela FIPECAFI-FEA-USP, situada no Departamento de Contabilidade e Atuária. A base de dados contém todos os detalhes sobre as demonstrações financeiras das empresas que atuam no mercado brasileiro.
} 
versus caixa, ludícibus (1989, p. 2) observa que "os contadores têm experiência em chegar ao fluxo de caixa a partir do regime de competência, mas não o caminho inverso".

Para um melhor entendimento desse cálculo, faz-se necessário retornar ao conceito do FCO indireto, pois esse utiliza uma série de elementos que estão disponíveis no balanço, na demonstração de resultados e na demonstração de origens e aplicações de recursos.

O FCO indireto é determinado a partir do lucro líquido e a evidenciação de, basicamente, dois grupos de ajustes. O primeiro grupo é composto pelas despesas e receitas constantes do resultado do exercício, mas que não afetam o caixa do próprio exercício (como, por exemplo, a despesa de depreciação). Ora, essas despesas e receitas guardam uma profunda semelhança com as despesas e receitas que são ajustadas na DOAR, uma vez que nessa demonstração os ajustes ao lucro líquido representam as despesas e receitas que não afetam o capital circulante líquido e, por conseqüência natural, obviamente também não afetam o caixa. Portanto, ao calcular o primeiro grupo de ajustes do cálculo do FCO indireto, o usuário utiliza as informações extraídas da DRE e também da DOAR.

O segundo grupo de ajustes do FCO indireto relaciona-se às variações dos ativos e passivos operacionais. Uma redução na conta de clientes impacta positivamente no caixa, uma redução no saldo de fornecedores gera um ajuste negativo ao lucro para que esse represente, adequadamente, as variações do caixa. Para que o usuário possa obter de maneira correta tais variações, basta verificar com cuidado o balanço patrimonial e identificar quais as contas dessa demonstração são referentes às operações da sociedade. Dessa maneira, de acordo com a lógica utilizada para o cálculo, basta computar tais variações e o resultado pode ser uma medida bastante aproximada do FCO.

\subsection{Críticas}

Em busca de uma validação empírica do FCO derivado de ajustes contábeis, Bahnson, Miller e Budge (1996) desenvolveram uma extensa pesquisa com demonstrações contábeis de quatro anos (de 1987 a 1990) publicadas nos Estados Unidos. O estudo, segundo os autores (Ibid..p. 1-2), foi estimulado pela identificação em alguns balanços divulgados, de algumas variações de contas operacionais, como contas a receber, por exemplo, as quais não coincidiam com a variação divulgada na DFC. Com base nisso, algumas questões surgiram, como: qual é a extensão dessas diferenças? Que fatores as causam e quais as suas conseqüências? Para responder a essas questões, realizaram a pesquisa em três estágios (Ibid., p. 2):

the first stage was an examination of a large sample of Compustat financial statements (...) the second stage was an in-depth analysis of the statements published by ten companies that identified a variety of causes for the nonarticulated changes that they reported (...) the third stage developed implications for education, accounting research and practice based on these findings ${ }^{6}$.

O termo nonarticulation (desarticulação) foi utilizado ao longo de todo o trabalho dos autores para se referir ao fato de as variações divulgadas na DFC não serem iguais às variações calculadas a partir dos balanços patrimoniais. O primeiro estágio da pesquisa se propôs a comparar o FCO publicado (reported operating cash flow - ROCF) com um cálculo semelhante ao exposto no início deste capítulo, efetuado para as demonstrações de quatro anos de uma base de dados norte-americana chamada Compustat. Os autores batizaram esse cálculo de Independently calculated operating cash flow - IOCF.

Uma amostra inicial totalizou 9.757 empresas e, adicionalmente, foi determinada uma sub-amostra, originada a partir da primeira, totalizando $7.861 \mathrm{com}$ panhias. Para a obtenção dessa sub-amostra, foram excluídas da amostra original as empresas que sofreram aquisições no período. Os autores justificaram a criação dessa sub-amostra pois (Ibid., p. 3) "an acquisition creates non-operating and nonarticulated changes in the acquirer's current accounts"7. O objetivo, com isso, foi o de concluir se as diferenças entre o ROCF e o IOCF se explicavam apenas pela questão das aquisições entre empresas.

\footnotetext{
6 "O primeiro estágio foi o exame de uma ampla amostra de demonstrações contábeis da base de dados Compustat (...) o segundo estágio foi uma análise detalhada das demonstrações publicadas por dez empresas, a qual identificou uma variedade de causas para as mudanças desarticuladas reportadas (...) o terceiro estágio desenvolveu implicações para o ensino, a pesquisa contábil e a prática baseadas nestas descobertas". Tradução livre.

7 “Uma aquisição cria mudanças não operacionais e desarticuladas nas contas correntes da empresa adquirente". Tradução livre.
} 
As diferenças determinadas nas duas amostras foram calculadas em percentual (dividindo-se a diferença calculada pelo ROCF) e apresentadas em uma distribuição de classes. Segundo os autores (Ibid., p.3-4):

the distributions reveal that about 25 percent of the data points in the primary sample and subsample have immaterial differences, which were defined as falling in the range from $-3 \%$ to $+3 \%$ of ROCF. The remaining points in the primary sample and subsample show material differences between IOCF and ROCF that are widely and nearly symmetrically distributed in the positive and negative directions. The distributions also show that between 16 percent and 18 percent of the data points in the two samples have differences with absolute values that exceed 100 percent of ROCF. In summary, this stage of the research showed that there is a wide distribution of differences between ROCF and IOCF, including many with significant magnitudes ${ }^{8}$.

A respeito da sub-amostra, concluiram os autores que:

excluding the acquisition companies caused nothing more than a slight shifting from each end of the distribution toward the middle (...) on the whole, the lack of a major change in the distribution indicates that factors other than acquisitions must be producing the differences 9 .

Desse modo, os autores passaram para o segundo estágio da pesquisa (Ibid., p. 4-6), em que selecionaram 10 empresas que produziram diferenças maiores do que $100 \%$ e analisaram detalhadamente as demonstrações contábeis a fim de identificar as causas de tais discrepâncias. Algumas das causas foram identificadas, como, por exemplo, reclassificações do imobilizado para o ativo circulante, dos estoques para o imobilizado. Porém, a grande maioria das diferenças não foi claramente identificada.

Com base nos dois estágios da pesquisa, os autores concluíram que (lbid., p. 6):

the published annual reports demonstrate that there is widespread and significant nonarticulation between published indirect cash flow statements and balance sheets. In addition, it is not possible to identify all of the factors that create the nonarticulation. At the very least, this finding justifies a conclusion that the conventional articulating indirect method is simply not applied in practice ${ }^{10}$.

O terceiro estágio da pesquisa preocupou-se com as implicações do resultado obtido para o ensino, a pesquisa e a prática. Resumidamente, os autores concluíram (Ibid., p. 6-13) que: as técnicas atuais de ensino da DFC são inadequadas pois não descrevem a prática atual de elaboração do método indireto e, portanto, deveriam ser redesenhadas; a utilidade das pesquisas já realizadas que utilizaram o IOCF ou algo semelhante é suspeita; e a flexibilidade do FASB quanto à escolha do método de divulgação da DFC é ineficaz e a DFC divulgada pelo método indireto não está atingindo seus objetivos .

Esses resultados podem estar, significativamente, afetados por um fator crucial: o enorme tamanho da base de dados utilizada pelos autores tornou inviável a leitura prévia das demonstrações contábeis. Porém, ao efetuar um cálculo aproximado de FCO a partir das demais demonstrações contábeis, o usuário faz uma leitura muito atenta dessas demonstrações a fim de identificar possíveis problemas relacionados ao fator da desarticulação entre a DFC e os balanços patrimoniais.

Desse modo, se a pesquisa fosse realizada com um número significativamente menor de empresas, porém com a possibilidade de uma análise prévia

\footnotetext{
8 "As distribuições revelam que aproximadamente $25 \%$ dos valores da primeira amostra e da sub-amostra têm diferenças imateriais, as quais foram definidas no intervalo de $-3 \%$ a $+3 \%$ do ROCF. Os valores remanescentes na primeira amostra e na sub-amostra mostram diferenças materiais entre o IOCF e o ROCF que são amplamente e aproximadamente simetricamente distribuídas nas direções positivas e negativas. As distribuições também mostram que entre 16\% e 18\% dos valores nas duas amostras têm diferenças em valores absolutos que excedem 100\% do ROCF. Em resumo, esse estágio da pesquisa mostrou que há uma ampla distribuição de diferenças entre o ROCF e o IOCF, incluindo muitas com magnitudes significativas”. Tradução livre.

9 “A exclusão das companhias com operações de aquisição não causou nada mais do que uma mutação desprezível de cada distribuição (...) em conjunto, a falta de uma grande mudança na distribuição indica que outros fatores além das aquisições devem estar produzindo as diferenças". Tradução livre.

10 "Os relatórios anuais publicados demonstram que há uma desarticulação vasta e significativa entre as demonstrações de fluxo de caixa e os balanços. Adicionalmente, não é possível identificar todos os fatores que criam a desarticulação. De qualquer modo, as descobertas justificam uma conclusão que a articulação convencional do método indireto simplesmente não é aplicada na prática". Tradução livre.
} 
das demonstrações contábeis a fim de melhor identificar os ativos e passivos genuinamente operacionais, é possível imaginar que as conclusões dos autores poderiam ter sido diferentes.

A respeito da dificuldade na identificação dos ativos e passivos relacionados às operações, Braga e Marques (2001b, p. 7-8) tecem alguns comentários, demonstrando, por exemplo, que as contas a receber podem, eventualmente, incluir, além das receitas de vendas, aplicações em títulos mobiliários, créditos oriundos da alienação de imobilizados ou participações societárias. O mesmo raciocínio é realizado pelos autores na análise das contas a pagar. Desse modo, concluem os autores que "extrair variações de ativos e passivos operacionais de balanços patrimoniais comparativos pode conduzir a enganos grosseiros em análises de tendências ou em simples comparações relativas. Um aprimoramento a este múltiplo consiste na decomposição de subgrupos circulantes por classes de transações, notadamente a partir das informações contidas em notas explicativas. Não obstante, a despeito de potencialmente reduzir a margem de enganos, esta tarefa pode dispender muito tempo ou ser dificultada pela ausência de dados em notas explicativas". O termo "múltiplo" utilizado pelos autores significa "medida alternativa que substitui um certo parâmetro para atender finalidades específicas".

Uma questão muito importante relacionada à identificação dos ativos e passivos operacionais referese à conta "fornecedores", que, conceitualmente, deveria registrar dívidas relacionadas ao fornecimento apenas de mercadorias destinadas à operação da companhia. Porém, na grande maioria das empresas, ela também capta dívidas com materiais de manutenção do imobilizado e até mesmo com o próprio imobilizado. Nesse caso, a consideração da variação dessa conta para o cálculo do FCO estaria incorreta, pois além de transações operacionais, o valor relaciona-se também a transações de investimento. A solução desse problema pode ser obtida caso a empresa possua um nível de evidenciação que permita a divulgação em notas explicativas ou no próprio balanço sobre a composição da conta "fornecedores".

Notadamente, a pesquisa realizada por Bahnson, Miller e Budge, citada anteriormente, pode ter sido atingida pelos "enganos grosseiros" a que Braga e
Marques se referem. Mas o "aprimoramento" citado pelos autores relaciona-se à cuidadosa identificação dos ativos e passivos operacionais com base em uma leitura criteriosa das demonstrações contábeis. Do ponto de vista conceitual, uma vez utilizado tal aprimoramento, a conclusão sobre o FCO derivado de ajustes contábeis é a de que essa medida pode representar uma aproximação muito razoável do FCO extraído da DFC. De outra maneira, pode-se afirmar que, conceitualmente, a hipótese nula relacionada ao FCO derivado de ajustes contábeis é aceita.

O objetivo da pesquisa empírica proposta neste trabalho é justamente o de testar essa afirmação com os dados da realidade. Uma vez que o número de empresas a ser utilizado nessa pesquisa é reduzido, é possível efetuar os cálculos do FCO de uma maneira mais criteriosa e cuidadosa.

\section{ESTUDO EMPÍRICO DAS EMPRESAS DO MERCADO BRASILEIRO}

Esta seção visa a, essencialmente, testar as hipóteses da pesquisa com dados reais, obtidos a partir de demonstrações contábeis de empresas do mercado brasileiro. Para efetuar esse teste, faz-se necessário descrever como a amostra de empresas foi selecionada e coletada e, além disso, demonstrar de que maneira foram tratados esses dados empíricos. Por fim, os testes estatísticos aplicados na amostra selecionada também são detalhados e é desenvolvida a análise dos dados.

\subsection{Seleção e Coleta dos Dados}

As demonstrações contábeis de empresas do mercado brasileiro vêm se desenvolvendo ao longo dos anos em relação à transparência das informações. Um exemplo disso é a própria divulgação da DFC, que, já há alguns anos, aparece em quadros suplementares.

Até 1999, porém, não havia normas contábeis brasileiras que discorressem a respeito da elaboração e divulgação da DFC. Com a publicação da NPC20, emitida pelo IBRACON em abril desse ano, supõe-se que as demonstrações posteriores a essa data incluam a DFC de acordo com tais padrões.

Em função da proximidade da publicação da NPC-20 com o encerramento das demonstrações 
contábeis de 31 de dezembro de 1999, essas poderiam, ainda, não estar ajustadas a um mesmo padrão contábil de elaboração e divulgação da DFC. Assim, foram selecionadas apenas as demonstrações contábeis de empresas que divulgaram a DFC nos períodos findos em 31 de dezembro de 2000 e 2001.

A partir disso, foi consultada a base de dados da FIPECAFI por entender que essa base contém um número de empresas cadastradas suficientemente grande para que a seleção dos dados pudesse ser significativa. Essa base de dados situa-se no Departamento de Contabilidade e Atuária da Faculdade de Economia, Administração e Contabilidade da Universidade de São Paulo e é atualizada pela Fundação e Instituto de Pesquisas Contábeis, Atuariais e Financeiras (FIPECAFI) todos os anos com as informações dos balanços de empresas do mercado brasileiro com o intuito principal de publicar a edição anual da Revista Exame - Melhores e Maiores.

Uma das classificações realizadas no cadastro de cada empresa e no sistema que alimenta o banco de dados trata da divulgação da DFC. Foi possível identificar, do universo de todas as empresas cadastradas, quantas divulgaram a DFC no conjunto das informações contábeis publicadas e, além disso, qual foi o método de divulgação dessa demonstração (direto ou indireto). Tais informações são apresentadas resumidamente na tabela abaixo:

\section{Tabela 1 - Publicações de DFC nas demonstrações financeiras encerradas em 31/12/2000 e 31/12/2001}

\begin{tabular}{c|ccc|c}
\hline \multirow{2}{*}{$\begin{array}{c}\text { Período de } \\
\text { Encerramento }\end{array}$} & \multicolumn{2}{|c|}{ Método } & \multirow{2}{*}{ Total } \\
\cline { 2 - 3 } & Direto & Indireto & \\
$31 / 12 / 2000$ & 2 & 40 & 42 \\
\hline $31 / 12 / 2001$ & 3 & 59 & 62 \\
\hline Total & 5 & 99 & 104 \\
\hline$\%$ Método & $5 \%$ & $95 \%$ & \\
\hline
\end{tabular}

Fonte: Base de dados da FIPECAFI

É interessante notar a diferença existente entre a quantidade de DFCs divulgadas pelo método direto e pelo indireto. Isso confirma a tendência existente nos Estados Unidos e em outros países que flexibilizam a escolha do método, deixando essa decisão para a empresa.

Outro fato curioso é o expressivo aumento de $48 \%$ das divulgações de 2001 em relação às de 2000 . Tal tendência evidencia que as empresas brasileiras, mesmo que em número reduzido, demonstram a importância da análise da DFC para o melhor entendimento do seu negócio.

Com o intuito de obter uma amostra de empresas com demonstrações que possam, de fato, trazer as informações mais precisas, são utilizadas na pesquisa apenas as sociedades que publicaram o parecer dos auditores independentes sem ressalvas, contendo o parágrafo de ênfase sobre a auditoria da DFC, também sem ressalvas. Desse modo, das 104 empresas da seleção inicial, apenas 70 (32 do período de 2000 e 38 de 2001) se enquadram na classificação dada acima ${ }^{11}$.

Além disso, muitas dessas empresas divulgam as suas informações contábeis relativas aos números da controladora e também do consolidado. Desse modo, quando possível, foi dada a preferência para as informações consolidadas. Porém, quando da não existência de informações consolidadas ou então da divulgação da DFC apenas da empresa controladora, foram utilizadas as informações da empresa controladora. Eventualmente, a empresa nem possui tal caracterização, uma vez que não possui participações em outras empresas. Apesar disso, a nomenclatura foi mantida, para que se possam diferenciar tais informações de outras que sejam de demonstrações consolidadas.

\subsection{Tratamento dos Dados}

Definida a amostra de empresas que divulgaram a DFC em 2000 e 2001 e apresentaram o parecer dos auditores independentes com o parágrafo de ênfase sobre a auditoria da DFC e sem ressalvas, a pesquisa evoluiu para a etapa seguinte: 0 desenvolvimento de uma planilha excel que pudesse, a partir das informações digitadas provenientes das demonstrações contábeis, calcular o fluxo de caixa operacional, para poder compará-lo ao fluxo de caixa operacional publicado.

${ }^{11}$ Para mais detalhes a esse respeito, vide Salotti (2003, p. 106-111). 
A digitação dos balanços foi feita de maneira muito criteriosa, já que cada balanço necessitava ser padronizado. Os ativos circulantes e realizáveis a longo prazo e também os passivos circulantes e exigíveis a longo prazo foram subdivididos em três grandes subitens: financeiro, operacional e não operacional. Por exemplo, no caso de contas do ativo circulante, aplicações financeiras foram classificadas no ativo circulante financeiro; clientes, no ativo circulante operacional; e imóveis destinados à venda, no ativo circulante não operacional. Esse tipo de separação é de fundamental relevância para a obtenção do fluxo de caixa operacional, uma vez que, para esse cálculo, são computadas apenas as variações dos itens operacionais do balanço patrimonial.

Não é difícil imaginar a padronização de 70 balanços de empresas de diferentes setores da economia como uma tarefa que envolve uma parcela considerável de julgamento, pois, para a determinação da separação entre o que é operacional e o que não é, faz-se necessário uma leitura adequada das demonstrações contábeis e, não menos importante, o conhecimento das normas específicas relacionadas a cada setor. Ainda assim, dependendo da abertura que cada empresa procedeu às contas do seu balanço, a escolha da classificação dessas contas torna-se uma tarefa quase impossível. Desse modo, para que a pesquisa pudesse ser continuada, definiu-se o seguinte pressuposto: todas as contas têm natureza operacional, a menos que as informações contidas no balanço suportem uma classificação diferente desta. Por exemplo, é quase unânime a quantidade de balanços que contêm a conta "outros", ou "outras contas a receber", ou ainda "outros créditos". De modo antagônico, é quase inexistente a empresa que fornece uma abertura ou, pelo menos, uma descrição a respeito de tais "outras contas". Utilizando o pressuposto assumido, tais contas foram classificadas no grupo operacional, uma vez que a probabilidade de o valor ser de natureza operacional é avaliada como maior do que a probabilidade de o montante possuir uma natureza financeira ou mesmo não operacional. Um outro exemplo que necessita ser simplificado utilizando-se o referido pressuposto é a conta "fornecedores", que pode receber transações não somente operacionais, como, por exemplo, o fornecimento de itens do ativo imobilizado. Do ponto de vista do nível de transparência e de qualidade da evidenciação das demonstrações contábeis, esse procedimento de divulgação é inadequado, pois comprime saldos que não deveriam ser comprimidos. Portanto, se a empresa apresentou uma composição mais detalhada dessa conta, a classificação foi realizada de acordo com a sua natureza. Caso contrário, ou seja, se a companhia divulgou apenas o saldo da conta "fornecedores" e não detalhou mais nada a respeito, esse valor foi considerado no grupo de contas operacionais.

A padronização da Demonstração do Resultado do Exercício, se comparada à do Balanço Patrimonial, é uma tarefa bem simples, já que não existem grandes diferenças de padrões de divulgação entre as empresas.

A Demonstração de Origens e Aplicações de Recursos (DOAR), também, tem uma participação fundamental na determinação do FCO. É nela que são detalhadas todas as despesas e receitas que não afetaram o Capital Circulante Líquido (CCL) e, por conseqüência, também não afetaram o caixa. Uma vez que esses ajustes da DOAR também fazem parte dos ajustes do cálculo do FCO, eles foram detalhados analiticamente com o objetivo de demonstrar quais são especificamente os ajustes computados no cálculo do FCO. As demais origens (dos acionistas e de terceiros) e as aplicações também foram cadastradas para que a variação do CCL pudesse ser comprovada.

Com as demonstrações contábeis padronizadas e digitadas no Excel, foi elaborada uma planilha para calcular o FCO, a qual executou a tarefa de recuperar o resultado líquido do período, os ajustes efetuados ao lucro (provenientes da DOAR) e as variações de todos os ativos e passivos considerados como de natureza operacional. Logicamente, os aumentos de ativos e diminuições de passivos foram computados como diminuições no cálculo do FCO, assim como as diminuições de ativos e aumentos de passivos foram registrados como aumentos.

O cálculo do FCO, representado pela sigla FCOC (Fluxo de Caixa Operacional Calculado, de acordo com as normas do FASB), foi processado e os resultados, comparados com o FCOP (Fluxo de Caixa Operacional Publicado), o qual foi extraído da DFC publicada no conjunto das demonstrações contábeis. Ressalte-se que, em alguns casos, houve a necessidade de uniformização do FCOC com o FCOP, pois 
algumas empresas divulgaram o FCO integrando ou não eventos/contas que, pela conceituação do trabalho, não foram coincidentes. Assim, o FCOP de algumas empresas foi ajustado de modo a viabilizar tal comparação.

Realizando uma breve comparação entre as diferenças existentes entre o FCOP e o FCOC, um item em especial recebeu destaque: a figura das despesas e receitas financeiras. $O$ ajuste das despesas $e$ receitas financeiras capturado da DOAR para o cálculo do FCO considera apenas as despesas e receitas de longo prazo, uma vez que apenas essas não afetam o CCL. As despesas e receitas de curto prazo, independentemente do desembolso financeiro ou não, afetam o CCL. Comparando o ajuste da DOAR relativo às despesas e receitas financeiras com o ajuste evidenciado na DFC, diferenças significativas apareceram. O motivo é muito simples: o ajuste do FCO deve incorporar todas as despesas financeiras não pagas e receitas financeiras não recebidas, mas o ajuste da DOAR demonstra apenas tais despesas e receitas de longo prazo. Sem a parcela de curto prazo das despesas financeiras não pagas e das receitas financeiras não recebidas, a tarefa de estimar o FCO a partir das demonstrações contábeis torna-se bem mais complicada.

Em função disso, a partir dos dados já existentes, surgiram duas novas medidas: FCOPA (Fluxo de Caixa Operacional Publicado Ajustado) e FCOCA (Fluxo de Caixa Operacional Calculado Ajustado). A palavra "ajustado", acrescentada às medidas, serve para indicar que tais montantes foram ajustados para eliminar o efeito das despesas e receitas financeiras da medida de fluxo de caixa operacional. Isso foi feito da seguinte maneira: do FCOC foi estornado o ajuste da DOAR que havia sido considerado para o cálculo. O resultado representaria o fluxo de caixa operacional considerando $100 \%$ das despesas e receitas financeiras. Desse subtotal, foram eliminadas todas as despesas e receitas financeiras (obtidas com os dados da DRE) e, com isso, o montante resultante, denominado FCOCA, representa o FCO calculado de acordo com o padrão do IASB, que faculta à empresa a consideração das despesas financeiras como atividades de financiamento e das receitas financeiras como atividades de investimento. Processo semelhante foi feito com o FCOP para a obtenção do FCOPA: estorno do ajuste de despesas financeiras não pagas e receitas financeiras não recebidas (identificado na DFC) e, posteriormente, a eliminação de todas as receitas e despesas financeiras advindas da DRE.

Com isso, foram obtidas duas comparações:

$$
\begin{aligned}
& \text { FCOP } \times \text { FCOC } \\
& \text { FCOPA } x \text { FCOCA }
\end{aligned}
$$

A seção seguinte demonstra os resultados obtidos com tais comparações e as análises obtidas a partir de tais resultados.

\subsection{Apresentação dos Resultados}

Os resultados das comparações entre as medidas apresentadas na seção anterior são evidenciados, inicialmente, em gráficos. Posteriormente, os resultados são testados estatisticamente com o intuito de avaliar se a tendência demonstrada nos gráficos realmente se comprova do ponto de vista estatístico, ou seja, se as diferenças obtidas são significativas ou não.

Os gráficos apresentados, a seguir, foram desenhados a partir das diferenças calculadas em percentual, uma vez que as diferenças em valores podem ter significados diferentes, dependendo do tamanho da empresa. Por exemplo, uma diferença de $\$ 5.000$ pode significar muito para uma empresa que publicou o FCO de $\$ 3.000$ (uma variação de $167 \%$ ). Todavia, a mesma diferença comparada a um FCOP de $\$ 3.000 .000$ resulta em uma diferença percentual mínima de 0,2\%. As diferenças foram agrupadas em blocos e apresentadas na forma de histograma.



Gráfico 1 - Diferença FCOP x FCOC em percentual

Esse gráfico demonstra que, das 70 empresas analisadas, apenas 29 apresentaram diferenças entre o FCOP e o FCOC de $-10 \%$ a $+10 \%$. E, ainda, 7 empresas evidenciaram diferenças menores do que $-100 \%$ ou maiores do que $+100 \%$. 


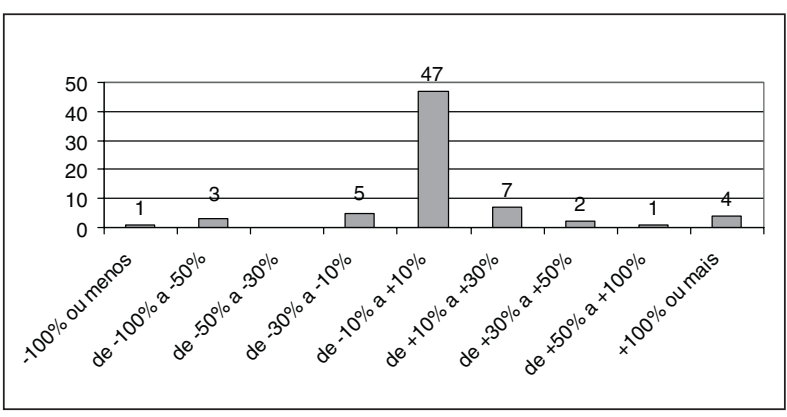

\section{Gráfico 2 - Diferença FCOPA x FCOCA em percentual}

O gráfico 2 evidencia que 47 empresas (das 70 analisadas) mostraram diferenças entre o FCOPA e o FCOCA de $-10 \% a+10 \%$. As demais diferenças se distribuíram quase homogeneamente no gráfico.

\subsection{Análise dos Resultados}

Os gráficos 1 e 2 referem-se à apresentação das diferenças entre o fluxo operacional publicado e o calculado a partir da técnica apresentada na seção 6. A diferença entre esses gráficos é que, no primeiro, o fluxo de caixa contém as despesas financeiras pagas e as receitas financeiras recebidas (de acordo com as normas do FASB). Já o segundo não contém nenhum tipo de despesa e receita financeira (padrão permitido pelas normas do IASB).

O gráfico 1 demonstra que das 70 empresas, apenas, 29 têm o seu FCO estimado próximo ao valor publicado dessa medida. Considerando esse cenário, é fácil concluir que a tentativa de estimar o FCO a partir das demais demonstrações contábeis não é tão simples como parece e pode levar o usuário de tal informação a enganos grosseiros. Mas, verificando, detalhadamente, a origem dessas diferenças, o ajuste das despesas e receitas financeiras se destaca como o mais significativo de todas as distorções. Isso ocorre porque o ajuste das despesas e receitas financeiras extraído da DOAR para o cálculo do FCO capta apenas as despesas financeiras não pagas e as receitas financeiras não recebidas de longo prazo. Porém, o FCOP reporta, na maioria das vezes, um valor muito diferente do ajuste da DOAR, uma vez que o FCO não faz distinção entre despesas e receitas de longo prazo e de curto prazo.

Desse modo, na tentativa (bem sucedida) de isolar o efeito dessa diferença para a determinação do
FCO, calcula-se o FCOCA e o FCOPA (o procedimento para o cálculo dessas medidas está apresentado na seção anterior). Com isso, a nova comparação não é afetada pela diferença das despesas e receitas financeiras, já que essas medidas "ajustadas" não contemplam o resultado financeiro. As distorções obtidas são apresentadas no gráfico 2, que demonstra uma sensível melhora em relação ao gráfico anterior, evidenciando que, das 70 empresas analisadas, o FCOCA se aproxima do FCOPA em 47 casos ( $67 \%$ do total). O segundo nível de diferenças (entre $-30 \%$ e $-10 \%$ e entre $+10 \%$ e $+30 \%$ ) capta 12 empresas (17\% do total) e apenas 11 casos apresentam estimativas ruins do FCOPA.

Sem dúvida, essa segunda comparação evidencia que, considerando as despesas financeiras classificadas nas atividades de financiamento e as receitas financeiras, nas de investimento, a estimativa do FCO a partir dos ajustes contábeis extraídos das demonstrações financeiras se torna uma poderosa ferramenta para quem não dispõe da DFC publicada.

Mas, as empresas que apresentam grandes diferenças ainda causam um certo desconforto. Afinal, quais são os motivos dessas distorções? Para responder a tal questão, o FCOPA das 11 empresas que apresentam diferenças abaixo de $-30 \%$ ou maiores do que $+30 \%$ foi comparado ao respectivo FCOCA e as ocorrências principais se encontram nas variações dos ativos e passivos operacionais. O motivo determinante da diferença em tais variações foi o baixo grau de evidenciação das informações contábeis prestadas pelas empresas. Em alguns casos, por exemplo, a DFC apresentada pela empresa não demonstra as variações analíticas dos ativos e passivos operacionais, evidenciando-as de maneira agrupada, o que obviamente dificulta a identificação dos problemas. Em outros casos, a abertura das contas dos ativos e passivos dada pela empresa no balanço patrimonial não é suficiente para que a separação entre contas operacionais e não operacionais seja feita adequadamente, o que pode influenciar, significativamente, a precisão do cálculo do FCO. Por exemplo, a dificuldade relacionada à identificação da composição do saldo de "fornecedores", já citada ao longo deste trabalho, pode trazer imprecisões significativas ao cálculo do FCO de empresas que utilizam essa conta para registrar transações operacionais e não operacionais mas não 
detalham esse procedimento e a composição do saldo em notas explicativas.

O mais importante é perceber que as distorções apresentadas no cálculo do FCO não ocorrem por problemas de inadequação do método desse cálculo. O resultado apresentado pela maioria das empresas inclusive prova tal adequação. As dificuldades existentes estão na qualidade e no detalhamento da informação contábil prestada pelas companhias.

\subsection{Testes Estatísticos Realizados}

A análise dos histogramas que representam o resultado da pesquisa realizada com as empresas do mercado brasileiro sinaliza fortemente para a aceitação da hipótese nula relacionada ao cálculo do FCO derivado de ajustes contábeis (mediante adoção do padrão determinado pelo IASB). Porém, essa sinalização deve ser testada estatisticamente para que a avaliação da significância das diferenças seja efetuada de uma maneira mais objetiva.

Assim, o teste de diferença de médias para dados emparelhados (do tipo paramétrico) é cogitado para ser utilizado. Porém, esse teste pressupõe que as diferenças tenham uma distribuição normal. Portanto, para que tal ferramental possa ser utilizado, são realizados os testes Qui-Quadrado e Kolmogorov-Smirnov com o objetivo de averiguar a normalidade das diferenças. Os resultados obtidos rejeitam a hipótese de tal normalidade e, com isso, o teste paramétrico não pode ser utilizado.

A partir desse resultado, são cogitados os testes não paramétricos, os quais não exigem pressupostos quanto à distribuição das variáveis testadas. $\mathrm{O}$ teste que mais se adapta ao problema dessa pesquisa é o teste dos sinais por postos de Wilcoxon, uma vez que esse teste analisa os dados pareados e leva em consideração a magnitude da diferença. Além disso, seu único pressuposto exige que a variável estudada seja contínua, o que, obviamente, é cumprido pelas diferenças estudadas.

O teste dos sinais por postos é amplamente descrito por Stevenson (1981, p. 311-15) e consiste basicamente em apurar as diferenças de cada par de observações e posteriormente separá-las em aumentos e decréscimos. Então, as diferenças são dispostas em postos, sem considerar os sinais e eliminando as diferenças nulas.
Como demonstra Stevenson (Ibid., p. 314):

Se a hipótese nula é verdadeira, é de esperar que os postos se repartam igualmente entre os valores + e - e que as duas somas sejam aproximadamente iguais. O que devemos determinar, então, é se a soma de postos escolhida difere demais da soma esperada para ser apenas atribuível ao acaso.

A soma total de postos, quando se dispõem $\mathrm{N}$ objetos consecutivamente em postos, começando com 1 e terminando com $\mathrm{N}$, é $[\mathrm{N}(\mathrm{N}+1)] / 2$.

Se $\mathrm{H}_{0}$ é verdadeira, a soma $U_{t}$, seja dos -'s ou dos +'s, deve ser igual à metade do total.

$$
U_{t}=\frac{1}{2}\left[\frac{N(N+1)}{2}\right]=\frac{N(N+1)}{4}
$$

Supondo $\mathrm{H}_{0}$ verdadeira, a diferença entre $U_{t}$ e o resultado observado para amostras de oito ou mais é aproximadamente normal, com desvio padrão $\sigma_{\mathrm{t}}$ dado por:

$$
\sigma_{t}=\sqrt{\frac{N(N+1)(2 N+1)}{24}}
$$

Se $\mathrm{H}_{0}$ verdadeira, a estatística teste $\mathrm{z}$ será aproximadamente normal com média 0 e desvio padrão 1,0.

$$
\begin{gathered}
Z=\frac{T-U_{t}}{\sigma_{t}} \\
Z=\text { (observado - esperado) / desvio padrão. }
\end{gathered}
$$

A idéia desse teste é que, se as diferenças não são significativas, elas estão distribuídas homogeneamente nos postos + e -. Para atestar se isso realmente acontece, basta calcular $U_{t}$ (que representa o valor esperado da soma de um dos postos) e a estatística $\mathrm{T}$ ( $\mathrm{O}$ valor real da soma de um dos postos).

Para que os valores da distribuição normal padrão possam ser utilizados, é necessário, ainda, "normalizar" a comparação entre o valor observado e o esperado. Para isso, basta dividir essa diferença pelo desvio padrão $\sigma_{t}$ de acordo com a fórmula descrita.

Uma vez calculada a estatística z (resultante da divisão indicada acima), esta deve ser comparada a um valor denominado "z crítico", que representa, na distribuição normal, os limites da região de aceitação da hipótese nula, ou seja, se a estatística z calculada estiver entre - $z$ crítico e + z crítico (região de aceitação), então a hipótese nula deve ser aceita. Caso contrário, a hipótese nula é rejeitada e se passa, então, a aceitar a hipótese alternativa. 
Os testes são realizados tanto para os valores nominais quanto para os percentuais das diferenças. $O$ nível de significância determinado é de $5 \%$ e a tabela, a seguir, demonstra o resumo desses testes, indicando a estatística z calculada (a partir do posto +), o valor de z crítico e o resultado (aceitação ou rejeição de $\mathrm{H}_{0}$ ).

Tabela 2 - Resultados do Teste dos Sinais por Postos de Wilcoxon

\begin{tabular}{l|c|c}
\hline Diferença Testada & Estatística z & z crítico \\
Diferença FCOP x FCOC (\$ mil) & $-5,37$ & 1,96 \\
\hline Diferença FCOP x FCOC (\%) & $-4,05$ & 1,96 \\
\hline Diferença FCOPA x FCOCA (\$ mil) & $-0,05$ & Rejeita H0 \\
\hline Diferença FCOPA x FCOCA (\%) H0 & 0,74 & Aceita H0 \\
\hline
\end{tabular}

Para a elaboração dessas tabelas, as diferenças foram, inicialmente, ordenadas e dispostas no seu respectivo posto (positivo ou negativo). As diferenças iguais a zero foram desprezadas e as demais foram numeradas de acordo com a ordem obtida. A soma de cada posto foi indicada como $T$ Observado e, além disso, foram calculados o T Esperado e o desvio padrão de T (de acordo com as fórmulas de $U_{t}$ e de $\sigma_{t}$ descritas por Stevenson). A estatística $Z$ foi obtida da diferença entre o $T$ Observado e o T Esperado dividida pelo Desvio Padrão de T.

O valor de "z crítico" de 1,96 refere-se ao limite inferior e superior da região de aceitação da hipótese nula relacionado ao nível de significância de $5 \%$, ou seja, se a estatística $Z$ encontra-se entre $-1,96$ e $+1,96$, então se aceita a hipótese nula. Caso contrário, aceita-se a hipótese alternativa. Em outras palavras, se a estatística $Z$ encontra-se entre -1,96 e +1,96, então se conclui que, ao nível de significância de $5 \%$, não há diferença significativa entre as duas medidas comparadas. Porém, se a estatística $Z$ for menor do que $-1,96$ ou maior do que $+1,96$, então, conclui-se: existe, de fato, diferença significativa entre as medidas.

Os resultados dos testes estatísticos confirmam a sinalização deixada pelos histogramas apresentados anteriormente. Dessa maneira, a partir da pesquisa empírica realizada com as 70 empresas brasileiras, a hipótese nula de que o FCO publicado é igual ao FCO calculado é aceita somente se esse fluxo operacional for obtido sem o efeito das despesas e receitas financeiras (padrão permitido pelas normas do IASB).

\section{CONSIDERAÇÕES FINAIS}

Este trabalho objetiva, primordialmente, a validação do FCO derivado de ajustes contábeis como uma medida alternativa para estimar o FCO extraído da DFC. Para tal, a partir de argumentação lógica e de uma pesquisa empírica, a hipótese nula de que o FCO Publicado é igual ao FCO derivado de ajustes contábeis foi testada.

A comparação da conclusão obtida no capítulo teórico com os resultados da pesquisa empírica implica que a tarefa de estimar o FCO, de acordo com as normas do FASB, por meio de ajustes contábeis obtidos das demais demonstrações contábeis pode levar o usuário de tais estimativas a enganos substantivos.

Já o FCO permitido pelas normas do IASB, que aceita a totalidade das despesas e receitas financeiras nas atividades de financiamento e investimento, respectivamente, pode, por meio do método de cálculo apresentado neste estudo, ser estimado com significativa precisão.

Ressalte-se que a precisão desse cálculo está diretamente relacionada ao nível da qualidade e do detalhamento das informações prestadas pelas empresas.

Uma outra constatação importante desse estudo é a verificação de que, nas publicações de DFCs no Brasil, ainda não existe um padrão, uma vez que são identificadas 11 das 70 empresas em que o FCOP sofre algum tipo de ajuste por estar em desacordo com um mesmo padrão. Esses ajustes são realizados para que haja uma padronização do FCO, necessária à viabilidade da comparação realizada. 
Essa realidade brasileira pode estar relacionada a, preponderantemente, duas questões: em primeiro lugar, em função da DFC ser recente (e ainda não obrigatória) no ambiente brasileiro, o conhecimento das normas para a elaboração e divulgação dessa demonstração ainda não está totalmente disseminado; além disso, a confusão existente na redação da NPC-20 do IBRACON acaba por sustentar diferentes padrões e, dessa forma, todos ficam suportados pela norma brasileira. A iminente inclusão da DFC como uma demonstração obrigatória no conjunto das demais informações contábeis justifica um aperfeiçoamento da NPC-20 para que o usuário possa utilizar uma informação correta e útil para as suas finalidades.

É importante ressaltar que o fator de sucesso fundamental para que o FCO derivado de ajustes contábeis possa ser aceito como uma medida que estima, com uma considerável razoabilidade, o FCO extraído da DFC é a leitura e a análise de cada uma das demonstrações contábeis utilizada neste estudo. Se os ativos e passivos não são, cuidadosamente, classificados de acordo com a sua natureza (financeira, operacional e não operacional), as variações calculadas no FCO podem ser seriamente deturpadas e, com isso, o resultado, por certo, invalida o cálculo do FCO derivado de ajustes contábeis (como outros trabalhos científicos já o fizeram ${ }^{12}$ ).

Percebe-se, dessa forma, que, acima do conhecimento do método utilizado para o cálculo do FCO extraído das demais demonstrações contábeis, está a Ciência Contábil e suas normas gerais e específicas. Sem o domínio desse arcabouço teórico e prático, a tarefa de estimar o FCO torna-se quase impossível.

Portanto, o resultado desta pesquisa prova que, a partir das demais demonstrações contábeis (Balanço Patrimonial, Demonstração de Resultados e Demonstração das Origens e Aplicações de Recursos) e, ainda, dispondo de um nível adequado de evidenciação das informações necessárias, é possível estimar o FCO extraído da DFC com razoável precisão.

Os resultados obtidos neste trabalho não devem ser interpretados como desestimulantes à divulgação da DFC. O processo de estimação do FCO requer muito tempo e conhecimento para quem necessita dessa informação. Além disso, está sujeito a falhas, dependendo do nível da evidenciação das informações contábeis. Não obstante, a DFC não é composta apenas pelo fluxo das atividades operacionais. Existem, também, os fluxos das atividades de investimento e de financiamento, os quais, sem dúvida, também têm grande utilidade para os usuários da Contabilidade. Desse modo, o fato de abordar, conceitualmente, a elaboração e divulgação da DFC e de evidenciar tantas dificuldades no processo de estimação do FCO traz ao estudo um elevado grau de colaboração para que a Contabilidade seja mais bem desenvolvida e possa, desse modo, cada vez mais, fornecer informações úteis e confiáveis.

\section{REFERÊNCIAS BIBLIOGRÁFICAS}

BAHNSON, Paul R.; MILLER, Paul B. W.; BUDGE, Bruce P. Nonarticulation in Cash Flow Statements and Implications for Education, Research and Practice. Accounting Horizons, December, v.10, n.4, 1996.

Avaliação da Liquidez das Empresas Através da Análise da Demonstração de Fluxos de Caixa. Caderno de Estudos FIPECAFI. São Paulo: FIPECAFI, ano14, nr.25, p. 6-23, 2001.

CASTRO, Cláudio de Moura. A prática da pesquisa. São Paulo: Mc Graw Hill do Brasil, 1978.

Comissão de Valores Mobiliários. Parecer de orientação $n^{\circ} 24$. São Paulo: Janeiro/1992. Disponível em <http:// www.cvm.gov.br>. Acesso em 11.05.2003.
FIPECAFI - Fundação Instituto de Pesquisas Contábeis, Atuariais e Financeiras. Aprendendo Contabilidade em Moeda Constante. Redação de Marina Mitiyo Yamamoto. São Paulo: Atlas, 1994.

GIL, Antônio Carlos. Métodos e técnicas de pesquisa social. São Paulo: Atlas, 1987.

Instituto dos Auditores Independentes do Brasil (IBRACON). Normas e Procedimentos de Contabilidade - NPC20 Demonstração dos Fluxos de Caixa. São Paulo: IBRACON, 1999.

INTERNATIONAL ACCOUNTING STANDARDS BOARD (IASB). International Accounting Standards 2002. London: International Accounting Standards Committee Foundation, 2002.

${ }^{12}$ Veja, por exemplo, Bahnson, Miller e Budge (1996). 
IUDíCIBUS, Sérgio de. Lucro Contábil - Crepúsculo ou Ressurgimento? Caderno de Estudos FIPECAFI. São Paulo: FIPECAFI, v.1, n.1, p. 1-5, 1989.

IUDÍCIBUS, Sérgio de, MARTINS, Eliseu, GELBCKE, Ernesto Rubens. Manual de contabilidade das sociedades por ações: aplicável também às demais sociedades. 6. ed. São Paulo: Atlas, 2003.

LAKATOS, Eva Maria e MARCONI, Marina de Andrade. Fundamentos da metodologia científica. São Paulo: Atlas, 1985.

MARTINS, Eliseu; SANTOS, Ariovaldo dos; GELBCKE, Ernesto R. O que esperar dos Balanços de 2002? IOB - Informações objetivas. Caderno Temática Contábil e Balanços. Boletins no 3/2003, pg. TC 1 - TC 6. São Paulo, mar. 2003

SALOTTI, Bruno Meirelles. Demonstração dos Fluxos de Caixa: Um Estudo Empírico Sobre o Fluxo de Caixa das Atividades Operacionais. 2003. Dissertação (Mestrado em Controladoria e Contabilidade) - Faculdade de Economia, Administração e Contabilidade da Universidade de São Paulo, São Paulo.
SALOTTI, Bruno Meirelles. O Fim da Correção Monetária Integral e seu impacto em alguns índices de análise de balanços. Anais do $2^{\circ}$ Seminário em Controladoria da USP. São Paulo: USP, 2002.

SANTOS, Ariovaldo dos. Distorções na Análise Financeira, no Cálculo de Dividendos e de Impostos Provocadas pela falta de reconhecimento da Inflação nas Demonstrações Contábeis. In: XXI ENCONTRO DA ASSOCIAÇÃO NACIONAL DE PÓS-GRADUAÇÃO E PESQUISA EM ADMINISTRAÇÃO, 1997, Rio das Pedras-RJ, 1997. Anais eletrônicos do XXI Enanpad, 1997. Disponível em <http://www.anpad.org.br/frame_enanpad97.html>. Acesso em 23.03.2004.

STEVENSON, William J. Estatística Aplicada à Administração. São Paulo: Harper \& Row do Brasil, 1981.

VERGARA, Sylia Constant. Projetos e relatórios de pesquisa em administração. 2. ed. São Paulo: Atlas, 1998.

\section{BIBLIOGRAFIA COMPLEMENTAR}

ANDRADE, Maria Margarida de. Como preparar trabalhos para cursos de pós-graduação. 3. ed. São Paulo: Atlas, 1999.

BARBIERI, Geraldo. Fluxo de Caixa - Modelo para Bancos Múltiplos. 1995. Tese (Doutorado em Controladoria e Contabilidade) - Faculdade de Economia, Administração e Contabilidade da Universidade de São Paulo, São Paulo.

. Lucro Inflacionário e Fluxo de Caixa. Caderno de Estudos FIPECAFI. São Paulo: FIPECAFI, nr.13, p. 1-21, 1996.

BILLINGS, Bruce K.; MORTON, Richard M. The Relation Between SFAS N $\mathrm{N}^{\circ} .95$ Cash Flow From Operations and Credit Risk. Journal of Business Finance \& Accounting. Vol.29, n. 5 e 6, June/July 2002.

BRAGA, Roberto.; MARQUES, José Augusto Veiga da Costa. A demonstração de Fluxos de Caixa no Brasil: uma comparação entre as normas de divulgação norte-americanas e os formatos utilizados no Brasil. Revista de Contabilidade do CRC-SP. São Paulo, 09/00, v.4, n.13, pp. 24-37, 2000.

. Fundamentos conceituais da demonstração dos fluxos de caixa: significado, vantagens e limitações. Algumas evidências. Caderno de Estudos FIPECAFI. São Paulo: FIPECAFI, v.8, nr.14, p. 30-43, 1996.

Investigação sobre a Relevância da medida do Fluxo de Caixa Operacional. Anais do Asian Pacific Conference on International Accounting Issues, Rio de Janeiro, 2001.

CAMPOS FILHO, Ademar. Demonstração dos fluxos de caixa: uma ferramenta indispensável para administrar sua empresa. São Paulo: Atlas, 1999

DRITNA, Ralph E. e LARGAY III, James A. Pitfalls in Calculating Cash Flow from Operations. The Accounting Review, v.60, n.2, April, 1985.

FINANCIAL ACCOUNTING STANDARDS BOARD (FASB) Accounting Standards. Current Text. John Wiley \& Sons, Inc., 2002/2003 Edition.
FREZATTI, Fábio. Contribuição para o Estudo da Complementaridade do Lucro e do Fluxo de Caixa na Gestão de Negócios no Ambiente Empresarial Brasileiro. 2001. Tese (Doutorado em Controladoria e Contabilidade) - Faculdade de Economia, Administração e Contabilidade da Universidade de São Paulo, São Paulo.

GIBSON, Charles H. Financial Reporting and Analysis: Using Financial Accounting Information. 8. ed. United States: SouthWestern College Publishing, 2001.

GUP, Benton E. e DUGAN, Michael T. The Cash Flow Statement: The Tip of an Iceberg. Business Horizons, v.31, n.6, novembro/ dezembro/1988.

HEATH, Loyd C. Let's scrap the "funds" statement. The Journal of Accountancy. October, 1978.

HENDRIKSEN, Eldon S. e BREDA, Michael F. Van. Teoria da Contabilidade. São Paulo: Atlas, 1999.

INSTITUTO DOS AUDITORES INDEPENDENTES DO BRASIL (IBRACON). Normas Internacionais de Contabilidade 2001: texto completo de todas as normas internacionais de contabilidade e interpretações SIC existentes em $1^{\circ}$ de janeiro de 2001. São Paulo: IBRACON, 2001.

KETZ, J. Edward e LARGAY III, James A. Reporting Income and Cash Flows from Operations. Accounting Horizons, Vol. 1, n.1, June, 1987.

LEVINE, David M., BERENSON, Mark L., STEPHAN, David. Estatística: Teoria e Aplicações usando Microsoft Excel em Português. Rio de Janeiro: Livros Técnicos e Científicos, 1998.

LUSTOSA, Paulo Roberto Barbosa. DOAR - uma morte anunciada. Caderno de Estudos FIPECAFI. São Paulo: FIPECAFI, v.9, nr.16, p.26-38, 1997.

Um Estudo das Relações Entre o Lucro Contábil, os Fluxos Realizados de Caixa das Operações e o Valor Econômico da Empresa: Uma Simulação Aplicada a um Banco Comerci- 
al. 2001. Tese (Doutorado em Controladoria e Contabilidade) Faculdade de Economia, Administração e Contabilidade da Universidade de São Paulo, São Paulo.

MAKSY, Mostafa M. Articulation Problems Between the Balance Sheet and the Funds Statement. The Accounting Review. Vol. 63, n.4, October, 1988.

MARQUES, José Augusto Veiga da Costa e BRAGA, Roberto. Demonstração dos Fluxos de Caixa: uma contribuição à alteração da legislação societária. Anais do Encontro da ANPAD. Rio de Janeiro, 2001.

Demonstração de fluxos de caixa: contribuição à nova lei das S.A. Conjuntura Econômica. Rio de Janeiro, v.55, n.1, p.48-54, jan, 2001.

MARTINS, Eliseu. Contabilidade versus fluxo de caixa. Caderno de Estudos FIPECAFI. São Paulo: FIPECAFI, v.11, n.20, p. 9-17, 1999.

Evolução (ou involução?) para o fluxo de caixa (primeira parte). $I O B$ - Informações Objetivas, Temática Contábil e Balanços. São Paulo: Boletim IOB 02/88, n.5, p.45-9, 1988a.

. Evolução (ou involução?) para o fluxo de caixa (segunda parte). $I O B$ - Informações Objetivas, Temática Contábil e Balanços. São Paulo: Boletim IOB 02/88, n.6, p.54-8, 1988b.

Evolução (ou involução?) para o fluxo de caixa (terceira parte). $I O B$ - Informações Objetivas, Temática Contábil e Balanços. São Paulo: Boletim IOB 02/88, n.7, p.62-7, 1988c.

Um Novo fluxo de caixa (FASB 95). IOB - Informações Objetivas, Temática Contábil e Balanços. São Paulo: Boletim IOB 05/88, n.13, p.124-9, 1988.

MARTINS, Gilberto de Andrade. Manual para elaboração de monografias e dissertações. 3. ed., São Paulo: Atlas, 2002.

MCENROE, John E. An Examination of Attitudes Involving Cash Flow Accounting: Implications for the Content of Cash Flow Statements. The International Journal of Accounting, v.31, n.2, 1996.

MOORHEAD, Cindy. The Cash Movement of Operating Activity. Business Credit. Vol.103, n.7, Jul/2001.

NURNBERG, Hugo. Inconsistencies and Ambiguities in Cash Flow Statements Under FASB Statement No. 95. Accounting Horizons, v.7, n.2, 1993.
NURNBERG, Hugo e LARGAY III, James A. Interest Payments in the Cash Flow Statement. Accounting Horizons, v.12, n.4, dezembro/98.

PRICE WATERHOUSE COOPERS (PWC). International Accounting Standards: Similarities and Differences - IAS, US GAAP and UK GAAP. PWC, February 2000.

RUE, Joseph C. e KIRK, Florence. Settling the Cash Flow Statement Dispute. National Public Accountant, v.41, n.6, junho/96.

SANTOS, Ariovaldo dos. DOAR x Fluxo de Caixa. IOB - Informativo Dinâmico. São Paulo, v.15, n.82, pp. 1247, 1991.

SANTOS, Ariovaldo dos e LUSTOSA, Paulo Roberto B. Demonstração dos Fluxos de Caixa: Alternativas para tratamento dos estoques - atividades operacionais ou de investimentos? IOB Informações Objetivas, Temática Contábil e Balanços. São Paulo: Boletim IOB 05/99, n.21, pp.1-8, 1999a.

Demonstração dos Fluxos de Caixa: uma reflexão sobre a objetividade (ou falta de) do fluxo de caixa. IOB - Informações Objetivas, Temática Contábil e Balanços. São Paulo: Boletim IOB 04/99, n.14, pp. 1-8, 1999b.

Juros e dividendos pagos: onde classificá-los na demonstração dos fluxos de caixa? IOB - Informações Objetivas, Temática Contábil e Balanços. São Paulo: Boletim IOB 09/99, v.33, n.39, pp. 1-7, 1999c.

SCHRICKEL, Wolfgang Kurk. Demonstrações financeiras: abrindo a caixa preta: como interpretar balanços para a concessão de empréstimos. 2. ed. São Paulo: Atlas, 1999.

SILVA, Cesar Augusto Tibúrcio, SANTOS, Jocineiro Oliveira dos e OGAWA, Jorge Sadayoshi. Fluxo de Caixa e Doar. Caderno de Estudos FIPECAFI. São Paulo: FIPECAFI, nr.9, p. 1-26, 1993.

WALLACE, R. S. Olusegun e COLLIER, Paul A. The "Cash" in Cash Flow Statements: A Multi-Country Comparison. Accounting Horizons. December, 1991.

YAMAMOTO, Marina Mitiyo. Demonstrações Financeiras Tradicionais e Fluxo de Caixa: semelhanças e conflitos. Anais do Congresso da ABAMEC. Águas de Lindóia, 1991.

ZELLER, Thomas L e STANKO, Brian B. Operating cash flow ratios measure a retail firm's "ability to pay". Journal of Applied Business Research. Vol.10, n.4, Fall 1994.

NOTA:

Endereço dos autores:

FEA-USP

Av. Prof. Luciano Gualberto, 908 - Butantã

São Paulo - SP

05508-900 